This item was submitted to Loughborough's Research Repository by the author.

Items in Figshare are protected by copyright, with all rights reserved, unless otherwise indicated.

\title{
Damage response of steel plate to underwater explosion: Effect of shaped charge liner
}

\section{PLEASE CITE THE PUBLISHED VERSION}

http://dx.doi.org/10.1016/j.ijimpeng.2017.01.008

\section{PUBLISHER}

(C) Elsevier

VERSION

AM (Accepted Manuscript)

\section{PUBLISHER STATEMENT}

This work is made available according to the conditions of the Creative Commons Attribution-NonCommercialNoDerivatives 4.0 International (CC BY-NC-ND 4.0) licence. Full details of this licence are available at: https://creativecommons.org/licenses/by-nc-nd/4.0/

\section{LICENCE}

CC BY-NC-ND 4.0

\section{REPOSITORY RECORD}

Zhang, Zhifan, Longkan Wang, and Vadim Silberschmidt. 2017. "Damage Response of Steel Plate to Underwater Explosion: Effect of Shaped Charge Liner”. Loughborough University. https://hdl.handle.net/2134/24684. 


\title{
Damage response of steel plate to underwater explosion: Effect of shaped charge liner
}

\author{
Zhifan Zhang, ${ }^{\mathrm{a}, \mathrm{b}}$, Longkan Wang ${ }^{\mathrm{a}}$, Vadim V. Silberschmidt ${ }^{\mathrm{b}, *}$ \\ ${ }^{a}$ College of Shipbuilding Engineering, Harbin Engineering University, Harbin 150001, China \\ ${ }^{\mathrm{b}}$ Wolfson School of Mechanical and Manufacturing Engineering, Loughborough University, Leicestershire LE11 3TU, UK
}

\author{
A B S T R A C T
}

\begin{abstract}
A shape of charge liners has a great effect on formation of a metal jet and its penetration into a target. In this paper, three different shapes of a charge liner, namely, conical, hemispherical and spherical-segment, are chosen to investigate their effect on damage response of a plate to underwater explosion. A Smooth Particle Hydrodynamic (SPH) method based on mesh-free Lagrange formulation is applied to simulate an entire process of a shaped-charge detonation, formation of a metal jet as well as penetration on a steel plate. Initially, a SPH model of the shaped charge with a spherical-segment liner is developed, and its results are compared with experimental data to verify the effectiveness of this method. Then, numerical simulations of shaped charges with different liners are performed to study the damage characteristics of a steel plate subjected to underwater-explosion shock loading and the metal jet. It was found that for the shock wave the peak value of the radial pressure is larger than that of the axial pressure during the detonation process; the level of pressure in the spherical-segment case was higher than that of the other two cases. After the detonation, the metal jet was gradually produced under the effect of the detonation wave. Three types of the metal jet - a shaped charge jet (SCJ), a jetting projectile charge (JPC) and an explosive formed projectile (EFP) - were formed corresponding to three cases with conical, hemispherical and spherical-segment liners. The obtained results show that the velocity and length of the SCJ in the conical case are greater than that of the other cases, and it therefore may lead to a larger penetration depth. In addition, the EFP has a better motion stability for a velocity difference in the spherical case is lower than that of the other two cases. Subsequently, the shock wave arrives at the plate earlier than the metal jet, which will cause deformation of the plate. Due to higher pressure, the shock wave in the sphericalsegment case has a stronger damaging effect on the plate than that in the other two cases. Finally, the metal jet reaches the plate causing a hole. Because of a wider jet head, the EFP results in a more serious damage to the plate. The suggested analysis and its results provide a reference for structural design of shaped charge warheads.
\end{abstract}

Keywords:

Shaped charge jet

Liner

Underwater explosion

Penetration

\section{Introduction}

Naval structures can be severely damaged by a shock wave [1-4] and a metal jet [5-6] associated with underwater explosion. The metal jet can be classified into three main modes Shaped Charge Jet (SCJ) [7-13], Jetting Projectile Charge (JPC) [14-20] and Explosive Formed Projectile (EFP) [21-27]. These three modes were studied by various researchers using experiments, theoretical analysis and numerical modelling. For the first mode, Green [8] gained a first successful x-ray radiograph of an aluminum SCJ in 1974. Masahide et al. [10] proposed numericalanalysis methods to investigate non-inhibited and inhibited conical shaped charges. Molinari [13] adopted a finite-element Lagrangian code to simulate formation, fragmentation and penetration in a plate of a shaped charge jet. In their research of the JPC, Liao et al. [14] combined numerical simulation and experiments to study properties of a shaped charge with a semi-spherical liner. Murphy [16] introduced a unified analytical approach to solve a problem of shaped-charge penetration in concrete. $\mathrm{Wu}$ et al. [19] utilized 3D LS-DYNA in their simulation of the entire process of collapse and break-up of the JCP. As for the research of the EFP, Yu et al. [22] carried out many penetration tests into rocks of different strengths. Johnson et al. [25] discussed some technical issues and showed results for 3D EFP computations. Lin 
et al. [27] analysed distributions of velocity and pressure theoretically, and the obtained analytical results agreed well with the experimental data. However, most of these studies were focused on cases of air explosion, with few published papers discussing the processes associating with underwater explosion.

It was found that various parameters [28-35], such as initiation modes, a charge length and a liner material, affect significantly a cumulative effect of a shaped charge. Li et al. [29] focused on the influence of annular multi-point initiation on formation of the EFP. Bai et al. [31] discussed the effect of interaction mechanism between a jet and a target on penetration performance of a shaped charge liner. Ayisit et al. [32-33] studied the effect of off-axis initiation for shaped charges with different L/D ratios. Wang et al. [35] conducted experiments to investigate penetration of shaped charges with different cone angles and liner materials into concrete target. A shape of the liner has an important effect on formation of a metal jet and its penetration performance as well. Fu et al. [20] used LS-DYNA software to investigate formation, elongation and penetration processes of rod-like jets with three jetting penetrator charges (JPCs) - spherical cone, truncated wide-angle and spherical-segment liners. The use of traditional finite-element software is limited by computational difficulties caused by grid distortion related to high deformations in highly nonlinear problems of shaped charges. A Smoothed Particle Hydrodynamics (SPH) method [2,4,7,36-39] has natural advantages in simulating underwater explosions and metal-jet penetration, since, thanks to its mesh-less nature, it is suitable for solving problems with large deformations while its Lagrangian formulation makes it easy to capture material interfaces.

Therefore, the SPH method was used to simulate the entire process of metal-jet evolution associated with underwater explosion penetrating a plate in this paper. First, after a brief overview of the SPH theory a simulation of a shaped charge with a spherical segment liner was performed, and its numerical results were compared with the experimental data to verify the validity and feasibility of the presented SPH method. Second, SPH models for three cases of shaped charges with different liners - conical, hemispherical and sphericalsegment - were developed to simulate the process starting with detonation to the jet penetration. Third, the effects of different liners on shock-wave propagation, formation of the metal jet and its penetration performance were analysed. The structure of the paper reflects this research process.

\section{Theory and numerical verification}

\subsection{Basic SPH equations}

In the SPH method, the state of a studied continuum volume can be represented by a system of arbitrarily distributed particles that can move according to external forces and internal interactions between them [40]. As a result, governing equations are transformed into corresponding integral forms by using a specially selected smoothing kernel function. A continuous function $f(x)$ and its derivative $\nabla \cdot f(x)$ can be discretized as [40]

$$
\begin{aligned}
& f\left(\mathbf{x}_{i}\right) \approx \sum_{j} \frac{m_{j}}{\rho_{j}} f\left(\mathbf{x}_{j}\right) W_{i j} \\
& \nabla \cdot f\left(\mathbf{x}_{i}\right) \approx \sum_{j=1}^{N} \frac{m_{j}}{\rho_{j}} f\left(\mathbf{x}_{j}\right) \cdot \nabla_{i} W_{i j},
\end{aligned}
$$

where $W_{i j}$ is the smoothed function of a pair of particles $i$ and $j$ (the cubic spline function is employed in this paper); $\rho$ and $\mathrm{m}$ denote the density and mass, respectively.

The standard SPH method is characterised by poor performance in solving problems with a large density ratio [41]. Hence, a modified SPH method [42] based on volume approximation is applied to simulate evolution of a shaped-charge jet associated with underwater explosion. The conservation of mass, momentum and energy can be expressed as [42]:

$\left[\begin{array}{c}\frac{\mathrm{d} \rho_{\mathrm{i}}}{\mathrm{dt}} \\ \frac{\mathrm{d} v_{\mathrm{i}}^{\mathrm{a}}}{\mathrm{dt}} \\ \frac{\mathrm{de}}{\mathrm{dt}}\end{array}\right]=\left[\begin{array}{c}\rho_{\mathrm{i}} \sum_{\mathrm{j}=1}^{\mathrm{N}} \mathrm{m}_{\mathrm{j}} \cdot v_{\mathrm{ij}}^{\mathrm{b}} \\ \left.-\sum_{\mathrm{j}=1}^{\mathrm{N}} \frac{\mathrm{m}_{\mathrm{j}}}{\rho_{\mathrm{j}}} \frac{\sigma_{\mathrm{i}}^{\mathrm{ab}}+\sigma_{\mathrm{j}}^{\mathrm{ab}}}{\rho_{\mathrm{i}}}+\Pi_{\mathrm{ij}}\right) \\ \left.\frac{1}{2} \sum_{\mathrm{j}=1}^{\mathrm{N}} \frac{\mathrm{m}_{\mathrm{j}}}{\rho_{\mathrm{j}}} \frac{\sigma_{\mathrm{i}}^{\mathrm{ab}}+\sigma_{\mathrm{j}}^{\mathrm{ab}}}{\rho_{\mathrm{i}}}+\Pi_{\mathrm{ij}}\right) v_{\mathrm{ij}}^{\mathrm{b}}\end{array}\right] \cdot \frac{\partial \mathrm{W}_{\mathrm{ij}}}{\partial x_{\mathrm{i}}^{\mathrm{b}}}$,

where $v, \mathrm{e}, \mathrm{t}, x$ denote the velocity, energy, time and coordinates, respectively; $\mathrm{a}$ and $\mathrm{b}$ indicate the directions along the axes; $\Pi_{\mathrm{ij}}$ is artificial viscosity [40]; $\sigma$ is the stress and it can be obtained by solving the constitutive model.

\subsection{Constitutive model}

The stress $\sigma$ for water and exploding gas is composed of isotropic pressure and viscous shear stress; since their viscosity is small, it can be ignored in analysis of strong impacts such as a case of a shaped-charge jet associating with underwater explosion. Therefore, the stress can be obtained by solving a problem with regard to pressure. Pressure of detonation products and water can be presented with the Jones-Wilkins-Lee (JWL) equation of state (EOS) [43] and the Mie-Gruneisen equation of state [44], respectively.

The JWL EOS [43] for explosive gas is expressed as

$\mathrm{P}=\mathrm{A}\left(1-\frac{\omega \eta}{\mathrm{R}_{1}}\right) \exp \left(-\frac{\mathrm{R}_{1}}{\eta}\right)+\mathrm{B}\left(1-\frac{\omega \eta}{\mathrm{R}_{2}}\right) \exp \left(-\frac{\mathrm{R}_{2}}{\eta}\right)+\omega \eta \rho_{0} \mathrm{e}$,

where $\rho_{0}$ is initial density; $\mathrm{A}, \mathrm{B}, \mathrm{R}_{1}, \mathrm{R}_{2}$ and $\omega$ are the fitting coefficients obtained from experiments; e is detonation energy per unit mass; $\eta$ is the ratio of the density of detonation products to the initial density of the original explosive. The values of these parameters used in simulations below are listed in Table 1.

The Mie-Gruneisen equation of state [44] for water is given by

$\mathrm{P}=\left\{\begin{array}{l}\frac{\rho_{0} \mathrm{C}_{0}^{2} \mu\left[1+\left(1-\frac{\gamma_{0}}{2}\right) \mu-\frac{\mathrm{a}}{2} \mu^{2}\right]}{\left[1-\left(\mathrm{S}_{1}-1\right) \mu-\mathrm{S}_{2} \frac{\mu^{2}}{\mu+1}-\mathrm{S}_{3} \frac{\mu^{3}}{(\mu+1)^{2}}\right]^{2}}+\left(\gamma_{0}+\mathrm{a} \mu\right) \mathrm{e}, \mu>0 \\ \rho_{0} \mathrm{C}_{0}{ }^{2} \mu+\left(\gamma_{0}+\mathrm{a} \mu\right) \mathrm{e}, \mu<0\end{array}\right.$

where $\rho_{0}, C_{0}, a, e$ and $\gamma_{0}$ are the initial density, sound velocity, volume correction coefficient, the specific internal energy per unit volume and Gruneisen coefficient, respectively; $S_{1}, S_{2}$ and $S_{3}$ are fitting coefficients; $\mu$ is the compression, $\mu=\eta-1$, where $\eta$ is the ratio of density before and after the explosion, Water is in a compressed state when $\mu>0$ while in an expanded one when $\mu>0$. The relevant parameters are shown in Table 2.

Apparently, for solids with high shear strength, contribution of

Table 1

Parameters in Jones-Wilkins-Lee EOS for explosive gas [43].

\begin{tabular}{lllllll}
\hline$\rho_{0}\left(\mathrm{~kg} / \mathrm{m}^{3}\right)$ & $A(\mathrm{~Pa})$ & $B(\mathrm{~Pa})$ & $\mathrm{R}_{1}$ & $\mathrm{R}_{2}$ & $\omega$ & $e(\mathrm{~J} / \mathrm{kg})$ \\
\hline 1630 & 3.74 & 3.75 & 4.15 & 0.90 & 0.35 & $6.0 \times 10^{6}$ \\
\hline
\end{tabular}

Table 2

Parameters in Mie-Gruneisen EOS for water [44].

\begin{tabular}{llllllll}
\hline$\rho_{0}\left(\mathrm{~kg} / \mathrm{m}^{3}\right)$ & $C_{0}(\mathrm{~m} / \mathrm{s})$ & $\gamma_{0}$ & $a$ & $S_{1}$ & $S_{2}$ & $S_{3}$ & $e(\mathrm{~J} / \mathrm{kg})$ \\
\hline 998 & 1480 & 0.5 & 0 & 2.56 & 1.986 & 1.2268 & 357.1 \\
\hline
\end{tabular}


Table 3

Parameters in Mie-Gruneisen EOS for steel and copper [45].

\begin{tabular}{llllll}
\hline Material & $\rho_{0}\left(\mathrm{~kg} / \mathrm{m}^{3}\right)$ & $\Gamma$ & $C_{s}(\mathrm{~m} / \mathrm{s})$ & $S_{s}$ & $e(J / \mathrm{kg})$ \\
\hline steel & 7890 & 1.587 & 3075 & 1.294 & 0 \\
copper & 8960 & 2.0 & 3940 & 1.489 & 0 \\
\hline
\end{tabular}

shear should be taken into consideration. In this paper, 1006 steel and copper are used as the materials of the plate and the liner, respectively. The stress can be presented as a combination of isotropic pressure $P$ and deviatoric stress tensor $S$. In terms of the pressure $P$, the Mie-Gruneisen EOS for solid media [45] is introduced in the following form:

$\mathrm{P}=\left(1-\frac{1}{2} \Gamma \eta\right) \cdot\left(\alpha \eta+\beta \eta^{2}+\gamma \eta^{3}\right)+\Gamma \rho \mathrm{e}$

where $\Gamma, \rho$ and $e$ denote the Gruneisen parameter, density and initial energy, respectively. When a solid is in an expansion state, that is $\eta \leq 0, \beta=\gamma=0$, otherwise,

$\alpha=\rho_{0} \mathrm{C}_{\mathrm{s}}^{2}$,

$\beta=\alpha\left[1+2\left(\mathrm{~S}_{\mathrm{s}}-1\right)\right]$,

$\gamma=\alpha\left[2\left(\mathrm{~S}_{\mathrm{s}}-1\right)+3\left(\mathrm{~S}_{\mathrm{s}}-1\right)^{2}\right]$,

where $\rho_{0}, C_{s}$ and $S_{s}$ are the initial density, linear participation coefficient of impact velocity and particles velocity and slope, respectively. The parameters related to the Mie-Gruneisen EOS for steel and copper are given in Table 3.

The deviatoric stress tensor $S$ of a solid can be calculated from the stress rate $\dot{S}$ by integration, with $\dot{S}$ obtained from the Jaumann stress rate [40]. The Johnson-Cook [46] model and a von Mises yield criterion were applied to calculate yield strength and determine whether the stress should be renewed through the comparison between von Mises stress $\sigma_{\text {Mises }}$ and yield strength $Y$. If von Mises stress was less than the yield strength, there was no need to modify the stress com-

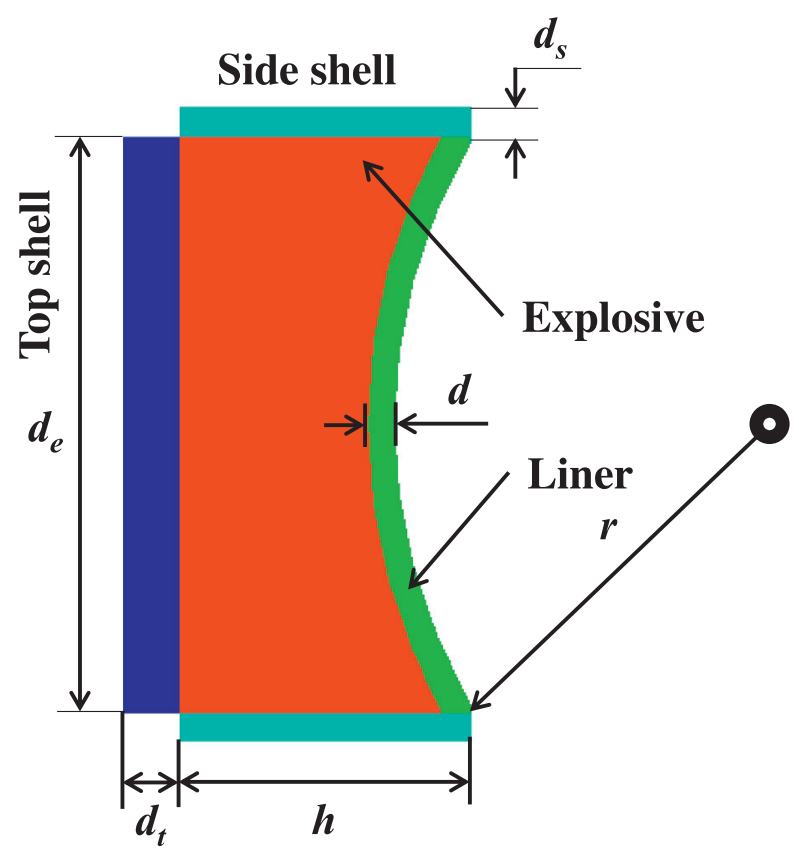

Fig. 1. Schematic of SPH model to simulate experiments in [48].

ponent. On the contrary, the deviatoric stress S should be modified [47]. The Johnson-Cook [46] model is given as

$$
Y=\left[\sigma_{0}+B_{0} \varepsilon_{e}^{n}\right]\left[1+C \ln \left(\dot{\varepsilon}_{e} / \dot{\varepsilon}_{0}\right)\right]\left[1-\left(T^{*}\right)^{M}\right],
$$

where $\sigma_{0}, C$ and $M$ denote the static yield strength, strain-ratestrengthening coefficient and thermal-softening coefficient, respectively; $B$ and $n$ are the strain-hardening exponents; $\varepsilon_{e}$ is the equivalent plastic strain, i.e. $\varepsilon_{e}=2 \sqrt{3 I_{2}} / 3$ ( $\mathrm{I}_{2}$ is the second invariant of the deviatoric stress tensor); $\dot{\varepsilon}_{e}$ and $\dot{\varepsilon}_{0}$ are the equivalent plastic strain rate and reference strain rate, respectively; $T^{*}$ is dimensionless temperature

Table 4

Parameters in Johnson-Cook constitutive model for steel and copper [46].

\begin{tabular}{llllllllll}
\hline Material & $\begin{array}{l}\sigma_{0} \\
(\mathrm{MPa})\end{array}$ & $\begin{array}{l}B_{0} \\
(\mathrm{MPa})\end{array}$ & $\begin{array}{l}\dot{\varepsilon}_{0} \\
\left(\mathrm{~s}^{-1}\right)\end{array}$ & $n$ & $\mathrm{C}$ & $M$ & $\begin{array}{l}T_{m} \\
(\mathrm{~K})\end{array}$ & $\begin{array}{l}T_{r} \\
(\mathrm{~K})\end{array}$ & $\begin{array}{l}C_{v} \\
(\mathrm{~J} / \mathrm{kg} \cdot \mathrm{K})\end{array}$ \\
\hline Steel & 350 & 275 & 1 & 0.36 & 0.022 & 1.0 & 1811 & 288 & 452 \\
Copper & 90 & 292 & 1 & 0.31 & 0.025 & 1.09 & 1356 & 288 & 383 \\
\hline
\end{tabular}

(a-1)

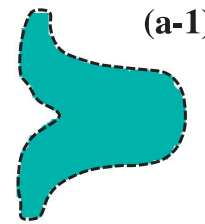

(a-2)

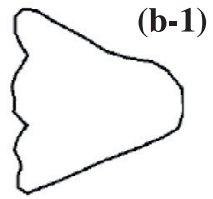

(b-2)

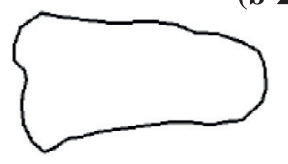

(b-3)

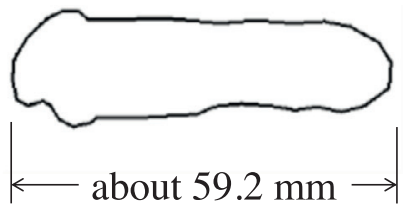

(1) $t \approx 50 \mu \mathrm{s}$

(2) $t \approx 70 \mu \mathrm{s}$

(3) $t \approx 100 \mu \mathrm{s}$

Fig. 2. Shape of metal jet at different moments: (a) numerical results; (b) experimental data. 

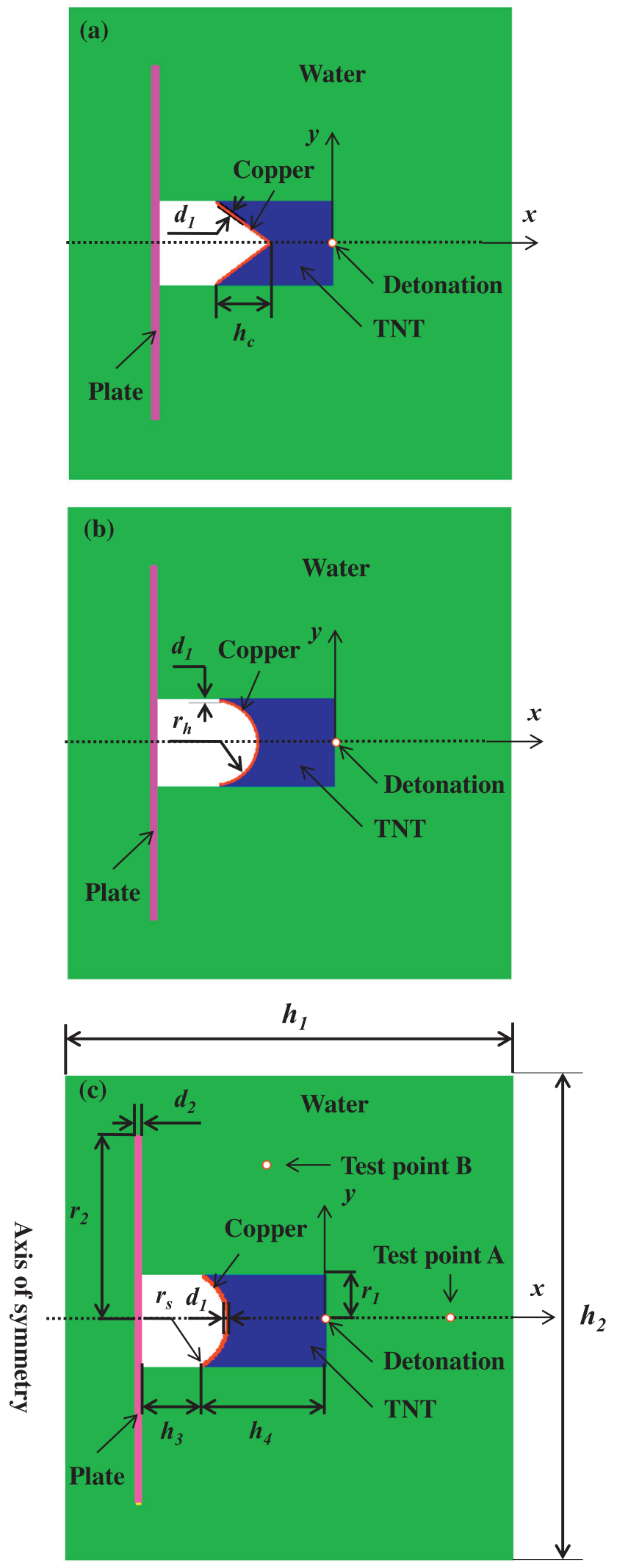

Fig. 3. Numerical models: (a) Case A; (b) Case B; (c) Case C.

corresponding to the current level $T$, i.e. $T^{*}=\left(T-T_{r}\right) /\left(T_{m}-T_{r}\right)$, where $T_{r}$ is room temperature, $T_{m}$ is the melting point and $T=T_{r}+\left(e-e_{0}\right) /\left(M C_{v}\right)$, where $e, e_{0}$ and $C_{v}$ denote specific internal
Table 5

Parameters in numerical model (in mm; see Fig. 3).

\begin{tabular}{llllllllll}
\hline$h_{1}$ & $h_{2}$ & $h_{3}$ & $h_{4}$ & $h_{c}$ & $d_{1}$ & $d_{2}$ & $r_{1}$ & $r_{2}$ & $r_{h}$ \\
\hline 190 & 200 & 20 & 40 & 17.3 & 1.0 & 2.0 & 15 & 60 & 15 \\
\hline
\end{tabular}

Table 6

Number of particles in SPH models of different cases.

\begin{tabular}{lllllll}
\hline \multirow{2}{*}{ Cases } & \multirow{2}{*}{ Liner } & \multicolumn{6}{l}{ Numbers of particles } \\
\cline { 3 - 7 } & & Water & TNT & Copper & Steel & Total \\
\hline Case A & Conical & 652,500 & 89,600 & 4791 & 24,000 & 770,891 \\
Case B & Hemispherical & 652,500 & 85,214 & 4520 & 24,000 & 766,234 \\
Case C & Spherical segment & 652,500 & 92,842 & 4054 & 24,000 & 773,396 \\
\hline
\end{tabular}

energy, initial specific internal energy and specific heat. Parameters of the Johnson-Cook model for steel and cooper are listed in Table 4.

\subsection{Numerical verification}

In order to verify the effectiveness of the developed SPH method, its numerical results were compared with the experimental data from [48]. The numerical model was developed according to the description in [48]; it is shown in Fig. 1. The magnitudes of length $h$ and diameter $d_{e}$ of the used explosive were respectively $30 \mathrm{~mm}$ and $60 \mathrm{~mm}$. The liner made of copper had a curvature radius $r=60 \mathrm{~mm}$ and thickness $d=2 \mathrm{~mm}$. Thicknesses of the top and side shells made of aluminium and steel were $d_{t}=6 \mathrm{~mm}$ and $d_{s}=3 \mathrm{~mm}$. A comparison of numerical and experimental results is illustrated in Fig. 2 for the moments corresponding to $50 \mu \mathrm{s}, 70 \mu \mathrm{s}$ and $100 \mu \mathrm{s}$ after the explosion.

The experimental results [48], shown as Fig. 2(b), were used to verify the results calculated with the SPH method. As Fig. 2(a-1) and (b-1) show, under the effect of a detonation wave, the liner converged to the axis of symmetry and the initial metal jet was formed as a result. Subsequently, as can be seen from Fig. 2(a-2), (b-2), (a-3) and (b-3), due to the difference in velocities of different parts, the metal jet elongated to several times of its initial length. It is obvious that the numerical results for the jet shape have a good agreement with the experimental data. Besides, the jet lengths obtained from the numerical simulations and in the experiment were respectively $58.1 \mathrm{~mm}$ and $59.2 \mathrm{~mm}$ with an error less than $2 \%$. In addition, the difference between the jet-head velocities in the experiment (about $2 \mathrm{~km} / \mathrm{s}$ ) and simulations (about $2.15 \mathrm{~km} / \mathrm{s}$ ) is less than $10 \%$. Consequently, the closeness of numerical results with the experimental ones presented in [48] proved the effectiveness and accuracy of the presented SPH method in solution of the problems of the shaped charge.

\section{Penetration of shaped charge jet into plate subjected to underwater explosion}

\subsection{Numerical models}

After the presented SPH was successfully verified, the effect of the shape of charge liners was studied for three cases of liners - conical (Case A), hemispherical (Case B) and spherical-segment (Case C), as discussed in this section. Sketches of the respective models developed to study the shaped-charge jet penetrating a plate subjected to underwater explosion are shown in Fig. 3; the magnitudes of geometrical parameters can be found in Table 5. The explosive material was TNT while the materials for the liner and the plate were copper and steel, respectively. TNT was detonated from the centre coinciding with the origin of coordinates. Test points $A$ and $B$ are located at positions $(28,0)$ and $(-16,43)$ (in $\mathrm{mm}$; see Fig. $3 \mathrm{c})$, respectively. The SPH models were discretized with non-uniform particle spacing, $0.1 \mathrm{~mm}$ for the plate, copper and TNT and $0.2 \mathrm{~mm}$ for water. The 

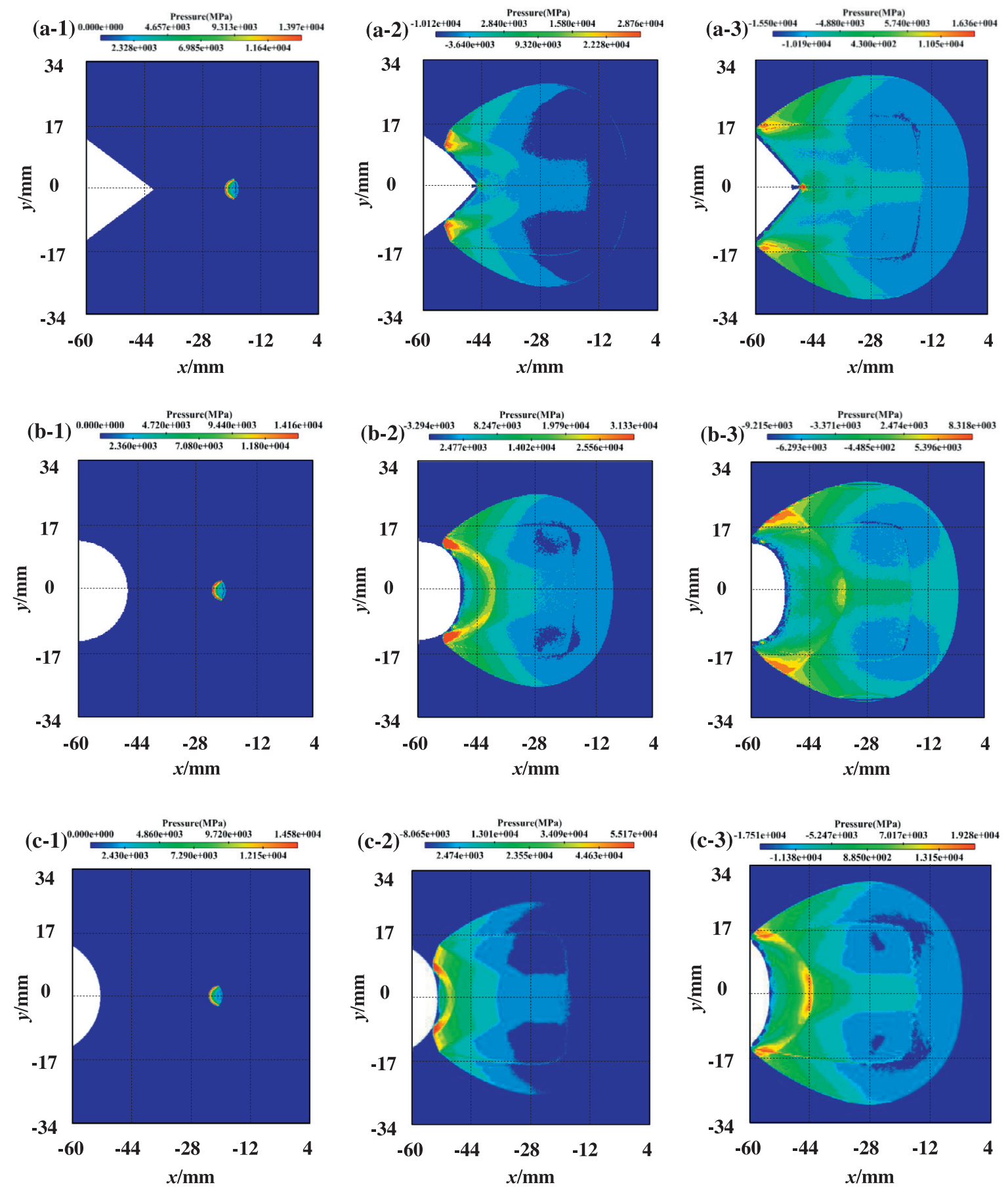

(1) $t \approx 0.4 \mu \mathrm{s}$

(2) $t \approx 5.2 \mu \mathrm{s}$

(3) $t \approx 6.4 \mu \mathrm{s}$

Fig. 4. Pressure distribution in explosion process: (a) Case A; (b) Case B; (c) Case C.

numbers of particles used in simulations of different cases are listed in Table 6.

\subsection{Shock-wave propagation in explosion process}

The detonation processes of the explosive for the three studied liners are shown in Fig. 4. Apparently, a spherical detonation wave was generated in the explosive, with the pressure up to $1.4 \mathrm{GPa}$ at around $0.4 \mu \mathrm{s}$. Meanwhile, a reflected wave was generated in water as well, with a velocity lower than that in the explosive. The reason for this phenomenon is the fact that surge impedance of water is lower than that of the TNT. After that, the detonation wave propagated with high speed and the explosion products continued to expand. As Fig. 4(a-2)-(c-2) show, the shock wave reached the liner and the pressure peak value soared up to about several GPasat about $5.2 \mu \mathrm{s}$. The figures also demonstrate that a rarefaction wave developed and propagated in the detonation products because of higher surge impedance of the liner than that of the explosive, and a low- 

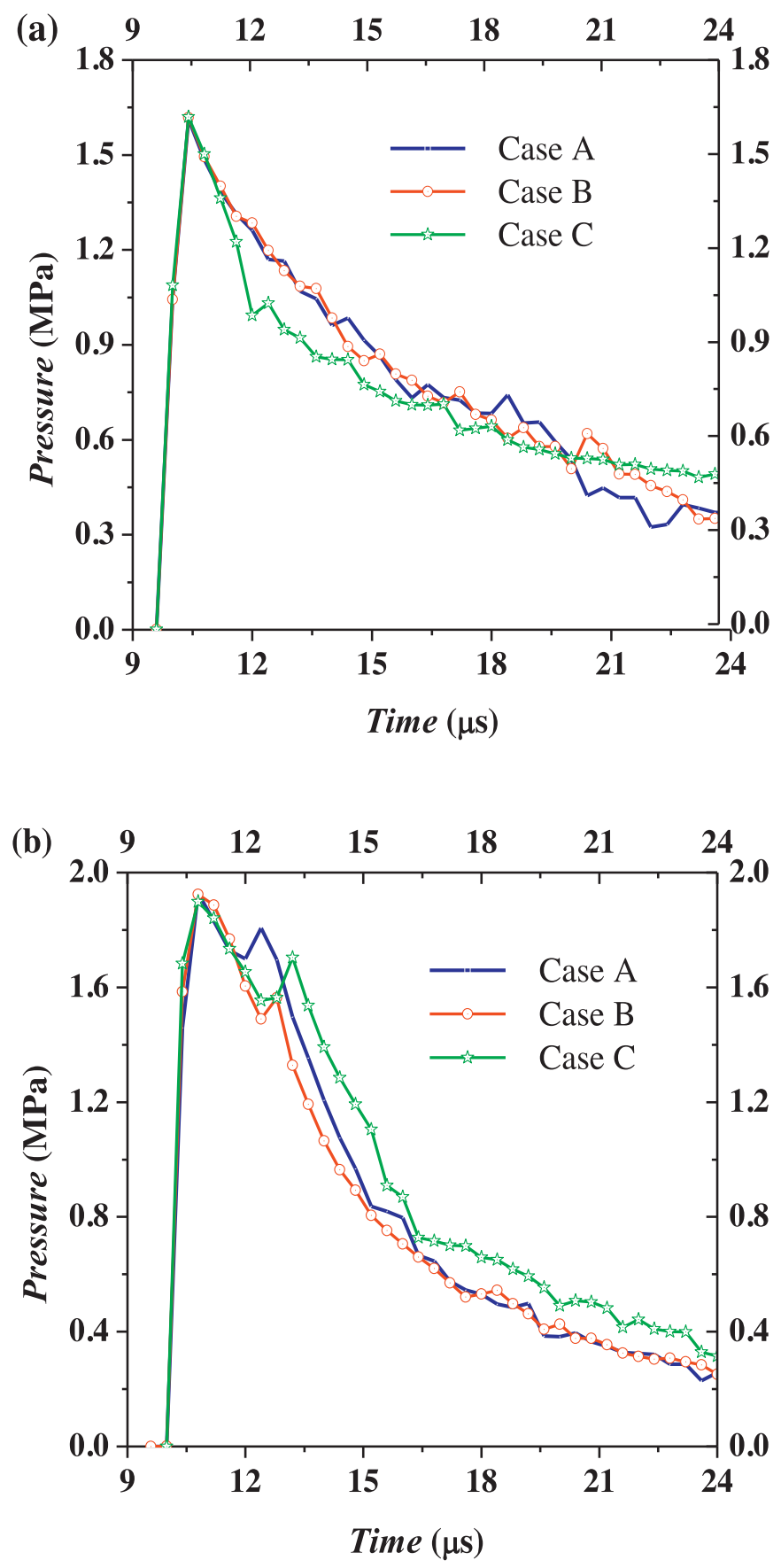

Fig. 5. Pressure-time curves: (a) point A; (b) point B.

pressure area was formed in the detonation products as a result. Comparing the three cases, it can be seen from Fig. 4(a-2) and (a-3) that the plastic flow of the liner was generated and accelerated under the tremendous pressure, and the initial metal jet was formed in Case A as a result. Still, as shown in Fig. $4 \mathrm{~b}$ and c, at that moment through the liners in Cases B and C were significantly affected, the initial jet was not formed yet. Finally, the detonation finished at around $6.4 \mu \mathrm{s}$ and the maximum pressure declined to about $1 \mathrm{GPa}$.

The history curves of shock-wave pressure at test points $A$ and $B$, which are located in the axial and radial directions in the water area and marked in Fig. 3c, are shown in Fig. 5. The shock wave arrived at point $A$ at around $10 \mu \mathrm{s}$ and the pressure shot up to about $1.6 \mathrm{MPa}$ (Fig. 5a). Subsequently, the level of pressure rapidly decreased and stayed steady eventually, corresponding to the predictions of propagation laws for shock waves. Point B was reached by the shock wave also at about $10 \mu \mathrm{s}$ as shown in Fig. 5b, with the pressure exceeding 1.9 MPa. There is also another peak in each pressure curve for this point: the first one is caused by the direct wave of the explosion, and the second one may just result from the second-wave propagation. As the detonation waves propagated from the explosion site through the water, the reflection waves were generated and, subsequently, converged at the TNT centre, leading to generation of compressive waves back into water again. A comparison of Fig. 5a and b demonstrates that the peak value of the radial pressure at point $B$ is higher than that of the axial peak value at point $A$.

\subsection{Formation of metal jet}

After detonation of the explosive, a metal jet was gradually formed under the effect of the detonation wave. In this section, the process of its formation is analysed based on simulation results. A velocity distribution for the liner at specific moments is shown in Fig. 6. During the initial formation of the metal jet (Fig. 6(a-1)-(c-1)), the liner was squeezed and plasticized under the effect of the detonation wave causing large deformations, with its top rolling over. As a result of axial tension and radial compression, the liner converged to the axis of symmetry and the initial metal jet began to form with high speed.

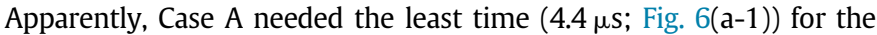
initial formation of the metal jet, faster than in Cases B (7.6 $\mu$ s; Fig. 6 (b-1)) and C (9.6 $\mu$ s; Fig. 6(c-1)).

When the jet velocity reached the maximum (see Fig. 6(a-2)-(c-2)), pressure transformed its original outer surface into the inner one as a result of a large deformation of the liner. Subsequently, the inner surface became the jet head with the metal jet elongated to several times of its initial length. Then, its velocity reached the peak values $4036 \mathrm{~m} /$ $\mathrm{s}, 2576 \mathrm{~m} / \mathrm{s}$ and $2743 \mathrm{~m} / \mathrm{s}$, respectively, for the three cases. It is obvious that the maximum velocity for Case A was higher than that for the other two cases.

The character of velocity distribution at the moment just before the jet penetrated the plate is shown in Fig. 6(a-3)-(c-3). At this stage, a shaped charge jet (SCI) was formed in Case A; it was thin and long and had a high speed (Fig. 6(a-3)). In Case B, a jetting projectile charge (JPC) was formed, with a wide jet head (Fig. 6(b-3)). In contrast, an explosive formed projectile (EFP) appeared at this stage in Case C, with a short jet length (Fig. 6(c-3)). In addition, the charge with the spherical segment liner was more suitable for long-distance movement than the other two cases because it had a smaller velocity difference of the jet head.

\subsubsection{Jet-head velocity}

Obviously, evolution of velocity is one of the most significant factors for the evaluation of the cumulative effects; thus, it is discussed in this section. The level of velocity of the jet heads increased significantly after the initial jet is formed, reaching its peak and declining thereafter under the effect of velocity gradient (Fig. 7). After the begin of plate penetration, the velocity reduced faster and eventually stayed steady. Comparing three curves of velocity evolution in Fig. 7, some different features can be highlighted. First, in Case A, the maximum velocity $(4036 \mathrm{~m} / \mathrm{s})$ is significantly higher than that in the other two cases $(2576 \mathrm{~m} / \mathrm{s}$ and $2743 \mathrm{~m} / \mathrm{s})$, defined by the phenomena observed in Fig. 6(a-2)-(c-2). Second, the jet in this case arrived at the plate faster, which can be observed from the time marked in Fig. 6(a-3)-(c-3) as well. Third, there was a little increase in the velocity level after the jet penetrated the plate in Cases B and C, other than Case A. This was probably due to the fact that the jethead velocity formed from the conical liner was higher, and the 

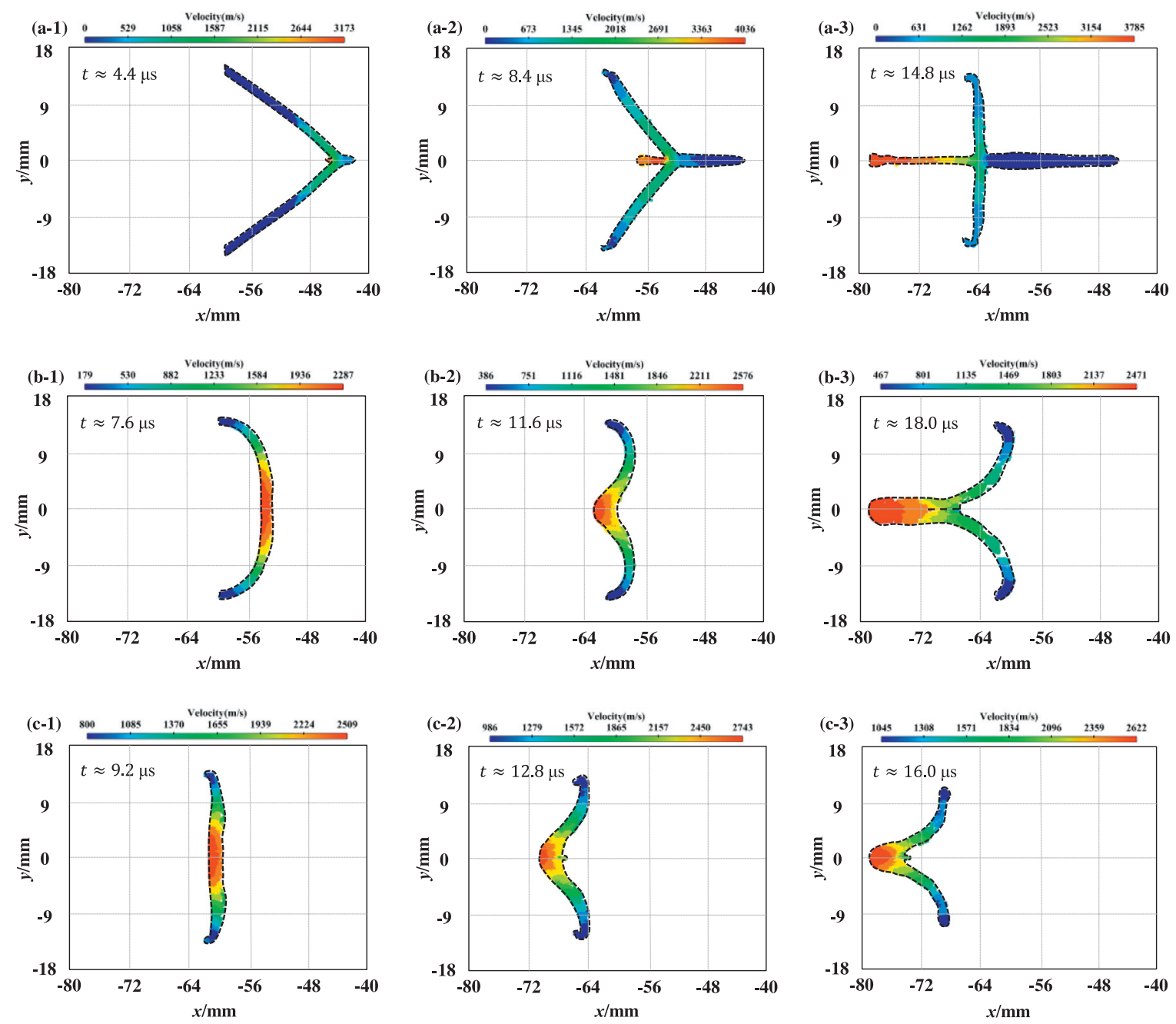

(1) Initial formation of jet

(2) Maximum velocity

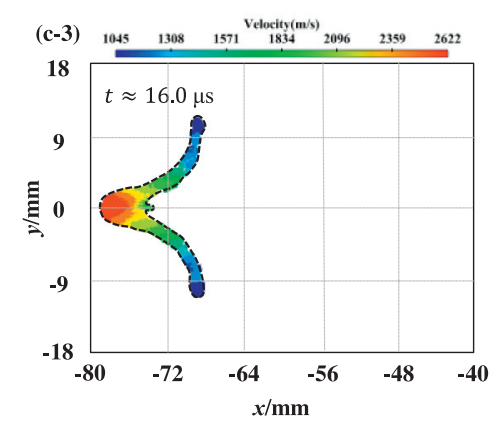

(3) Before penetration

Fig. 6. Velocity distribution in liner during the formation of metal jet: (a) Case A; (b) Case B; (c) Case C.

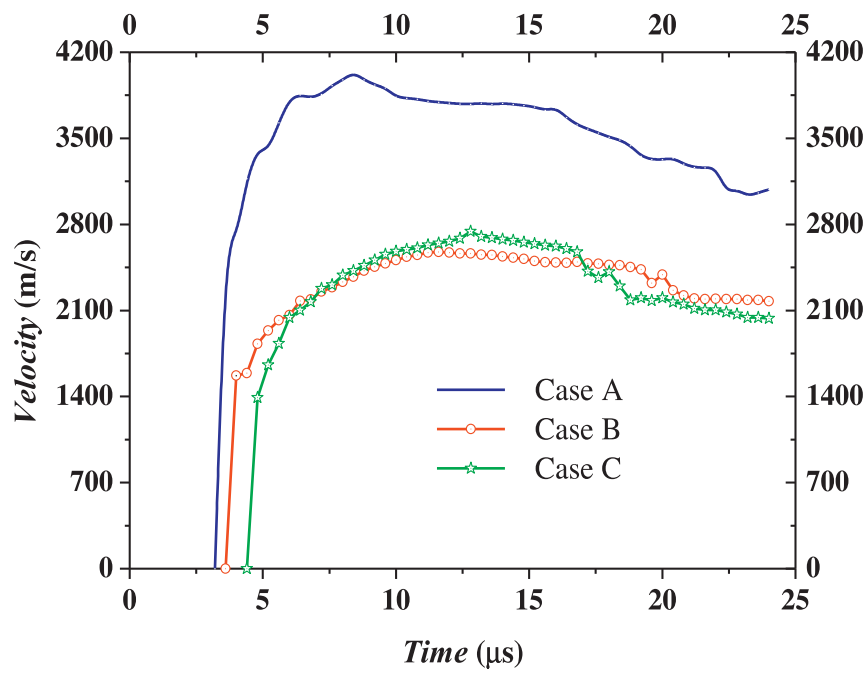

Fig. 7. Velocity-time curves of jets for various liners.
craterphenomenonwasnotobviousasaresult.Finally,theresidualvelocities were about $3084 \mathrm{~m} / \mathrm{s}, 2175 \mathrm{~m} / \mathrm{s}$ and $2035 \mathrm{~m} / \mathrm{s}$, respectively, for the threecasesofliners, indicatingthatvelocityevolutioninCaseAwascharacterizedbythehighermagnitudesduringtheentireprocess,anditmight causealargerpenetrationdepthasaresult.

\subsubsection{Length of jet head}

Jet length is an important factor in underwater explosion as well. To characterise jet evolution in the three studied cases, two dimensionless parameters were introduced: $L_{h}$ and $L_{\mathrm{f}}$ - the jet-head length and the jet length normalized with the diameter of TNT, respectively. The jet-head length in Case A increased with time, continuously other than in two other cases demonstrating stages of the increase followed by the decrease after the peak (Fig. 8a). The reason for this could be that the jet-head velocity in Case A was much higher. Besides, the peak point corresponds to the moment when the metal jet started penetrating the plate (Fig. 6). Apparently, the jet length increased with time for all the three liners (Fig. 8b). At $t \approx 24.0 \mu \mathrm{s}$, the following values of the jet length were reached: $L_{h}=1.62,0.83$ 

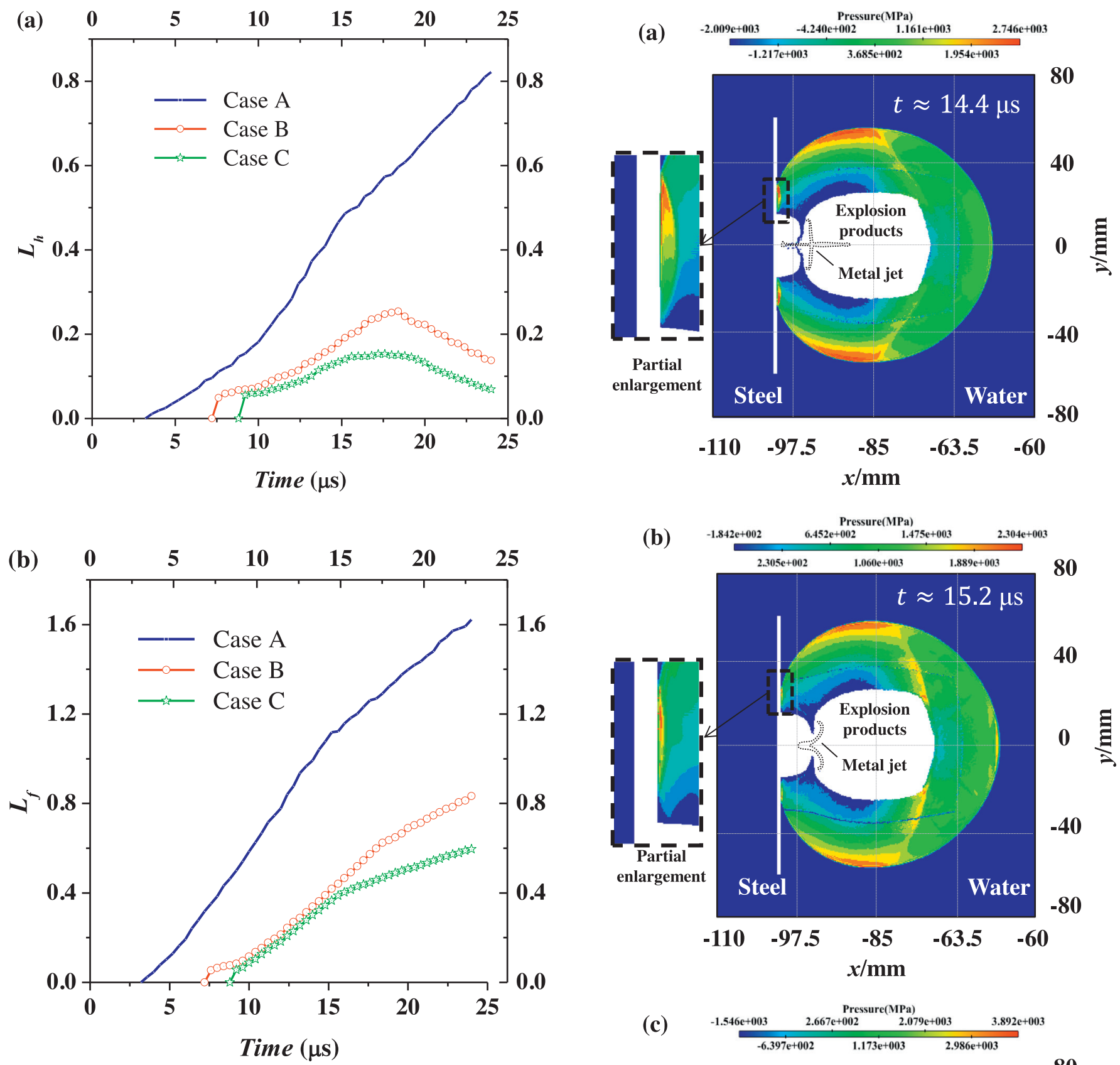

Fig. 8. Evolution of jet dimensions: (a) jet-head length; (b) jet length.

and 0.60 , respectively. It indicates that the higher the jet-head velocity, the longer the jet head length, and the bigger the penetration depth is, as a result.

\subsection{Metal-jet penetration into plate}

There are two types of loads generated after formation of a metal-jet, namely, underwater shock-wave loading and a metal jet, both causing damage in the plate during the process of a metal-jet penetration into it. Hence, load characteristics of jet penetration are analysed in this section.

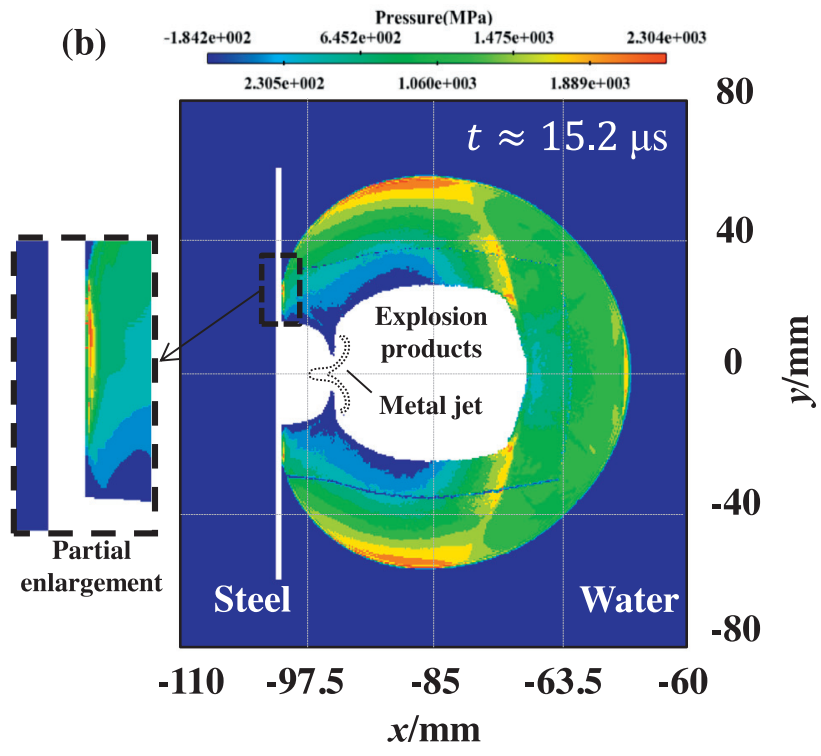

(c)
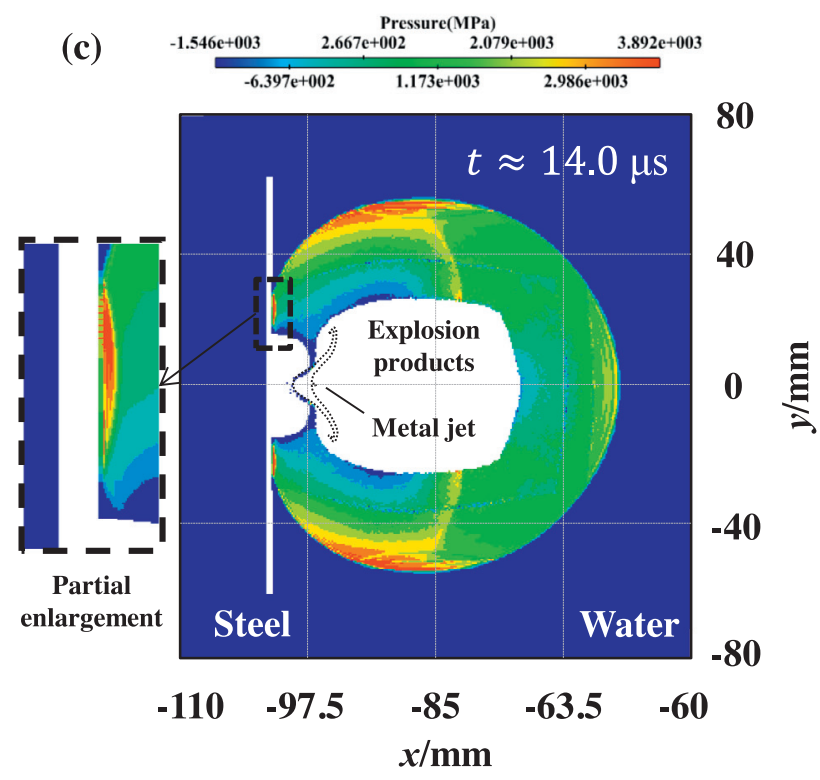

Fig. 9. Pressure distribution when shock wave reaches plate: (a) Case A; (b) Case B; (c) Case C. 


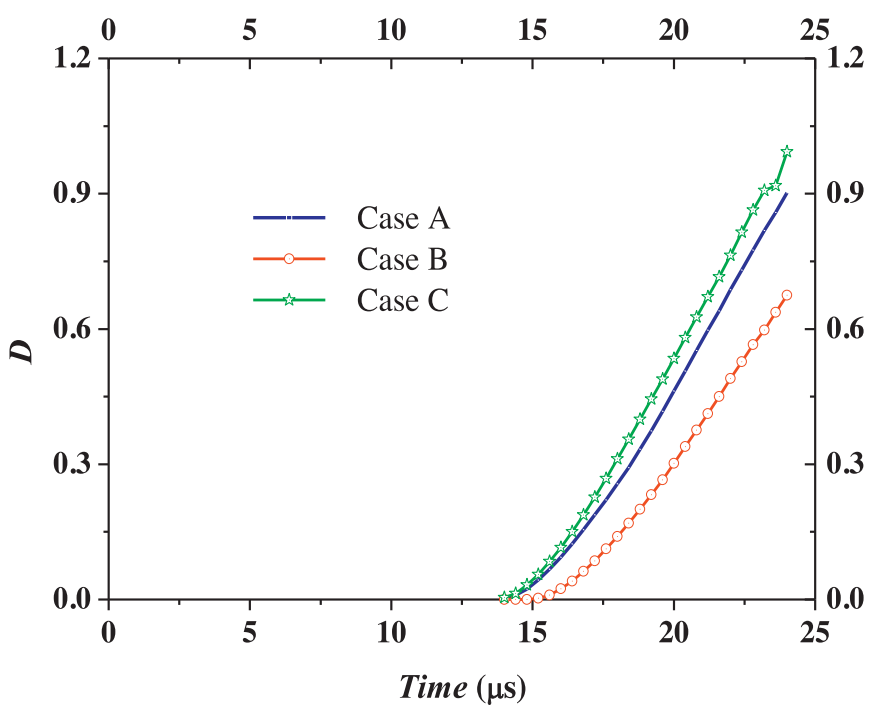

Fig. 10. Evolution of maximum deflection with time for various liners.

\subsubsection{Damage from underwater shock-wave loading}

Pressure distribution in water when the shock wave arrived at the plate is shown in Fig. 9; apparently, a transmitted wave was generated. Meanwhile, due to higher surge impedance of steel than water, a reflected wave was generated in the latter. Besides, the shock wave reached the plate faster than the metal jet. The comparison of the three cases demonstrates that the shock wave in Cases $A$ and $C$ reached the plate almost at the same time, different from Case $\mathrm{B}$. In addition, the pressure peaked at about $4 \mathrm{GPa}$ in Case $\mathrm{C}$, which is higher than that in Cases A (2.7 GPa) and B (2.3 GPa).

The initial deformation of the plate was caused by the underwater shock wave; the respective deflection curves are shown in Fig. 10 (here, the dimensionless parameter $D$ is the ratio of the maximum deflection of the plate and the diameter of TNT). This parameter rose with time for all the three cases of liners. The metal jet in Case B arrived at the plate at $14.0 \mu \mathrm{s}$, later than in the other two cases - at $14.4 \mu \mathrm{s}$ and $15.2 \mu \mathrm{s}$, corresponding to the moments in Fig. 9. Besides, the deflection in Case $C$ was larger than that in the other two cases, corresponding to the pressure peak in Fig. 9. It indicates that the larger the pressure peak of the shock wave, the larger the deflection of the plate. At about $24.0 \mu \mathrm{s}$, the magnitudes of $D$ for three cases were about $0.90,0.68$ and 0.99 , respectively; thus, the deflection in Case C had the maximum value, i.e. the shock wave in this case induced a higher damage in the plate.

\subsubsection{Penetration analysis}

After the shock wave arrived at the plate, the metal jet started penetrating it. The diagrams of distribution of von Mises stresses in the plate and the liner are presented in Fig. 11. As the metal jet began to damage the plate, the stress levels reached several GPas(Fig. 11(a-1)-(c-1)). Besides, it is clear that there were two shock waves propagating in the plate - one as a result of underwater shock wave, another generated in the plate by the metal jet. As a result, the material around the penetration site was squeezed, forming a bulge (Fig. 11(a-2)-(c-2)). At the same stage, the jet head developed into a 'mushroom'. Because of accumulation of the metal jet, the penetration was impeded and the damage zone grew larger with the increased radial velocity of the metal jet up to the full penetration of the plates (Fig. 11 (a-3)-(c-3)).

The comparison of penetration for the three cases shows that the penetration duration was $1.6 \mu \mathrm{s}, 2.8 \mu \mathrm{s}$ and $2.0 \mu \mathrm{s}$, respectively. It means that the SCJ with a high velocity penetrated the plate faster than the JPC and the EFP. Besides, thanks to the thinner and longer jet, the jet head of the SCJ was crushed resulting in the irregular shape. On the contrary, owing to their wide and short jet heads, the shape of the JPC and the EFP remained smooth. Additionally, because of the large velocity difference for the SCJ and the JPC, a crack occurred in the tail of the metal jet, indicating that the shaped charge with the spherical-segment liner (Case $C$ ) had the best motion stability.

Evolution of damage zones in the plate is presented in Fig. 12, in terms of their dimensionless sizes at the front and the back of the plate (normalized with the plate thickness), denoted as $C_{f}$ and $C_{b}$, respectively. Apparently, these zones increased with time and saturated eventually. The rate of the growth in the early stage of penetration was higher than that in the later stage (Fig. 12a). The SCJ arrived at the plate earlier, at about $15.2 \mu \mathrm{S}$, followed by the JPC at about $16.4 \mu \mathrm{s}$, which corresponds to the moments observed in Fig. 11. The magnitudes of $C_{f}$ were 3.84, 4.16 and 4.40 at around $24.0 \mu \mathrm{s}$, respectively, for Cases A, B and $C$, indicating that the plate penetrated by the EFP suffered the greatest damage. Parameters for the back of the plate (Fig. 12b) have a similar tendency as on its front, albeit being somewhat smaller. The maximum values of $C_{b}$ reached $3.47,3.65$ and 4.02 at around $24.0 \mu \mathrm{s}$, respectively. In other words, the EFP caused the largest damage zone for the three cases studied.

\section{Conclusion}

An SPH method with mesh-free and Lagrange formulation was utilized to simulate the entire process of such a complex physical phenomenon as a metal-jet penetration of an underwater plate. In order to investigate the effect of liners with different shapes on formation of the metal jet and its penetration performance, three cases with different shapes of the liner - conical (Case A), hemispherical (Case B) and spherical segment (Case C) - discussed in this paper. The main conclusion can be drawn as:

(1) The results from the numerical calculations in SPH-based simulation of EFP formation are all in good agreement with the experimental results, thus verifying the feasibility and effectiveness of the presented SPH method.

(2) Three modes of the metal jet were developed - Shaped Charge Jet (SCJ), Jetting Projectile Charge (JPC) and Explosive Formed Projectile (EFP) - corresponding to differently shaped liners in Cases A, B and C, respectively.

(3) The shock wave reached the plate earlier than the metal jet, and caused the initial deformation as a result. In addition, due to the higher pressure, the shock wave in Case $\mathrm{C}$ led to a larger deflection of the loaded plate.

(4) In terms of the jet-head and residual velocities, the SCJ with its higher velocity in Case A caused a larger penetration depth. As for the dimensions of the damage (penetration) zone and motion stability, the EFP with a wider jet head and a lower velocity difference in Case $\mathrm{C}$ caused more serious damage in the structure.

\section{Acknowledgement}

This work is supported by the National Natural Science Foundation of China (U1430236, 51479041, 51279038). 

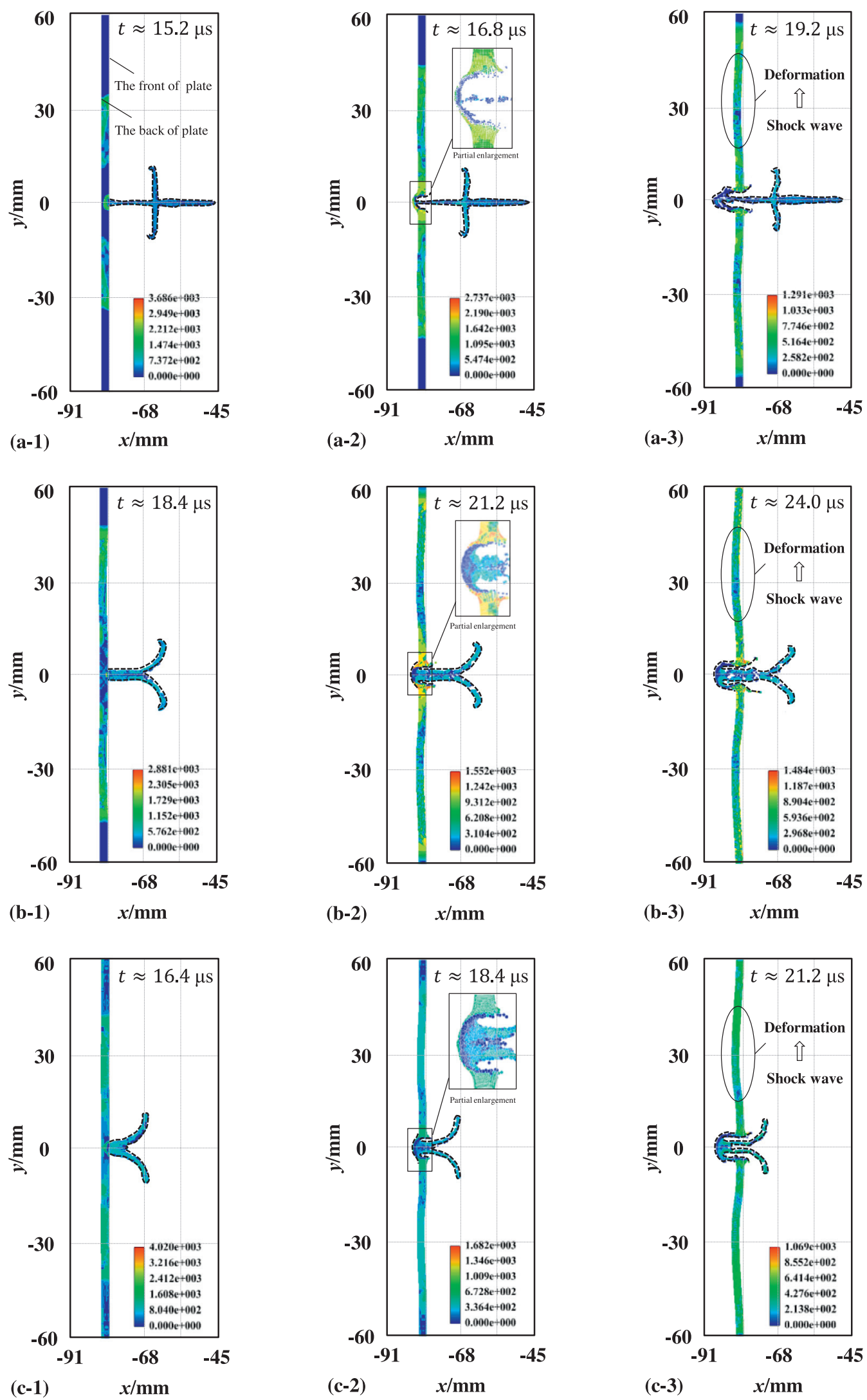

Fig. 11. Distribution of von Mises stress (in MPa) in process of metal-jet penetration of plate: (a) Case A; (b) Case B; (c) Case C. 

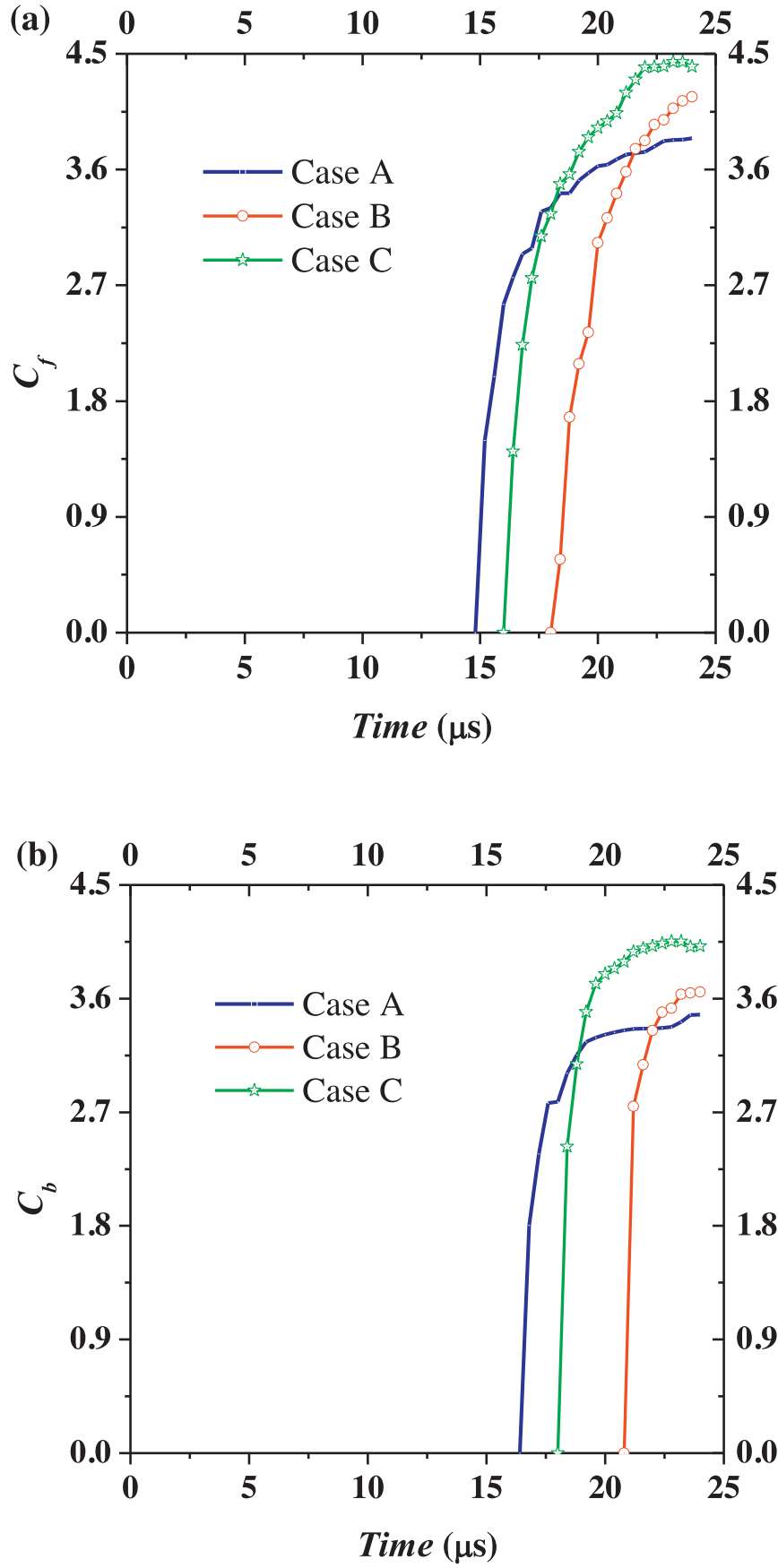

Fig. 12. Evolution of damage zone at front (a) and back (b) surfaces of plate.

\section{References}

[1] Zhang AM, Zhou WX, Wang SP, Feng LH. Dynamic response of the non-contact underwater explosion on naval equipment. Marine Struct 2011:24:396-411.

[2] Liu MB, Liu GR, Lam KY, Zong Z. Smoothed particle hydrodynamics for numerical simulation of underwater explosion. Comput Mech 2003;30:106-18.

[3] Rajendran R, Narasimhan K. Damage prediction of clamped circular plates subjected to contact underwater explosion. Int J Impact Eng 2001;25:373-86.

[4] Zhang AM, Yang WS, Yao XL. Numerical simulation of underwater contact explosion. Appl Ocean Res 2012;34:10-20.

[5] Pei MJ, Li CB. Experimental investigation of SCRSP penetrating the compound target with water interlayer. Chin J Explosiv Propell 2008;31:15-9.

[6] Kovarik R. Further experimental investigations of underwater reactive shaped charge liners and aluminum particle combustion during hypervelocity water impact and penetration. University of Illinois at Urbana-champaign; 2014.
[7] Feng DL, Liu MB, Li HQ Liu GR. Smoothed particle hydrodynamics modeling of linear shaped charge with jet formation and penetration effects. Comput Fluids 2013;86:77-85.

[8] Green Jr RE. First X-ray diffraction photograph of a shaped charge jet. Rev Sci Instrum 1975;46:1257-61.

[9] Hornemann U, Holzwarth A. Shaped charge penetration in alumina targets. Int ] Impact Eng 1997;20:375-86.

[10] Katayama M, Kibe S. Numerical study of the conical shaped charge for space debris impact. Int J Impact Eng 2001;26:357-68.

[11] Arnold W, Rottenkolber E. High explosive initiation behavior by shaped charge jet impacts. Procedia Eng 2013;58:184-93.

[12] Chen Q Liu K. A high-resolution Eulerian method for numerical simulation of shaped charge jet including solid-fluid coexistence and interaction. Comput Fluids 2012;56:92-101.

[13] Molinari JF. Finite element simulation of shaped charges. Finite Elements Ana Des 2002;38:921-36.

[14] Liao HP, Huang ZX, Zhang XF, Zeng CH. Rod-like jet properties of semispherical liner shaped charge. J Projectiles Rockets Missiles Guidance 2008;28:91-4 (in Chinese).

[15] Alekseevskii VP. Penetration of a rod into a target at high velocity. Combus Explosion Shock Waves 1966;2:63-6.

[16] Murphy MJ. Shaped-charge penetration in concrete: a unified approach. CA (USA): Lawrence Livermore National Lab.; 1983.

[17] Klopcic JT, Reed HL. Historical perspectives on vulnerability/ lethality analysis. U. S. Army Research Laboratory ADA361816; 1999.

[18] Daniels AS, Baker EL, Vuong TH, Chin CL, Fuchs BF, DeFisher SE. Selectable initiation shaped charges. Selectable initiation shaped charges. 20th international symposium on ballistics. Florida: NDIA; 2002. p. 23-7.

[19] Wu HL, Duan ZP, Wang YQ. Simulation investigation of rod-like jets. Explosion Shock Waves 2006;26:328-32 (in Chinese).

[20] Fu JP, Chen ZG, Hou XC, Li SQ, Li SC, Wang JW. Simulation and experimental investigation of jetting penetrator charge at large stand-off distance. Defence Technol 2013;9:91-7.

[21] Hussain G, Hameed A, Hetherington JG, Barton PC, Malik AQ. Hydrocode simulation with modified Johnson-Cook model and experimental analysis of explosively formed projectiles. J Energetic Mater 2013;31:143-55.

22] Yu C, Tong YJ, Yan CL, Li FB, Gui YL, Zhang M, et al. Applied research of shaped charge technology. Int J Impact Eng 1999;23:981-8.

[23] Weimann K. Research and development in the area of explosively formed projectiles charge technology. Propellants Explosiv Pyrotech 1993;18:294-8.

[24] Wu J, Liu JB, Du YX. Experimental and numerical study on the flight and penetration properties of explosively-formed projectile. Int J Impact Eng 2007;34:1147-62.

[25] Johnson GR, Stryk RA. Some considerations for 3D EFP computations. Int J Impact Eng 2006;32:1621-34

2.7 [26] Pappu S, Murr LE. Hydrocode and microstructural analysis of explosively formed penetrators. J Mater Sci 2002;37:233-48.

[27] Lin JJ, Shen ZW, Ren HQ, Wang CC, Yu L. Mechanism discussion on explosively formed projectile with fins by affixing partition. Blasting 2013;30:48-53 (in Chinese).

[28] James HR, Mellor C, Goff MJ. The effect of failure diameter on the initiation of explosives by shaped charge jets. Shock compression of condensed matter-2011: proceedings of the conference of the American physical society topical group on shock compression of condensed matter. AIP Publishing; 2012. p. 291-4

[29] Li WB, Wang XM, Li WB. The effect of annular multi-point initiation on the formation and penetration of an explosively formed penetrator. Int J Impact Eng 2010;37:414-24

[30] Walters WP, Golaski SK. Hemispherical and conical shaped-charge liner collapse and jet formation. Army Ballistic Research Lab Aberdeen Proving Ground MD 1987.

[31] Bai X, Liu JX, Li SK, Lv CC, Guo WQ, Wu TT. Effect of interaction mechanism between jet and target on penetration performance of shaped charge liner. Mater Sci Eng: A 2012;553:142-8.

[32] Ayisit $O$. The influence of asymmetries in shaped charge performance. Int J Impact Eng 2008;35:1399-404.

[33] Ayisit O, Coruh MM. Investigation of off-axis initiation of long $\mathrm{L} / \mathrm{D}$ hemispherical shaped charge warheads. Procedia Eng 2013:58:487-95.

[34] Held M. Liners for shaped charges. J Battlefield Technol 2001;4:1-7.

[35] Wang C, Ma TB, Ning JG. Experimental investigation of penetration performance of shaped charge into concrete targets. Acta Mechanica Sinica 2008:24:345-9.

[36] Zhang AM, Yang WS, Chao H, Ming FR. Numerical simulation of column charge underwater explosion based on SPH and BEM combination. Comput Fluids 2013;71:169-78.

[37] Qiang HF, Wang KP, Gao WR. Numerical simulation of shaped charge jet using multi-phase SPH method. Trans Tianjin Univ 2008;14:495-9.

[38] Liu MB, Liu GR, Zong Z, Lam KY. Computer simulation of high explosive explosion using smoothed particle hydrodynamics methodology. Comput Fluids 2003;32:305-22.

[39] Zhang AM, Sun PN, Ming FR. An SPH modeling of bubble rising and coalescing in three dimensions. Comput Meth Appl Mech Eng 2015;294:189-209.

[40] Liu GR, Liu MB. Smoothed particle hydrodynamics - a meshfree particle method Singapore: World Scientific Publishing Co. Pte. Ltd; 2003

[41] Liu MB, Liu GR. Smoothed particle hydrodynamics (SPH): an overview and recen developments. Archives Comput Methods Eng 2010;17:25-76.

[42] Zhang ZF, Sun LQ Yao XL, Cao XY. Smoothed particle hydrodynamics simulation of the submarine structure subjected to a contact underwater explosion. Combust Explosion Shock Waves 2015;51(4):502-10. 
[43] Dobratz BM. LLNL explosive handbook: properties of chemical explosives and explosives and explosive simulants, Livermore, Calif, USA: Report UCRL 52997 Lawrence Livermore National Laboratory; 1981.

[44] Steinberg DJ. Spherical explosions and the equation of state of water. Livermore, CA: Lawrence Livermore National Laboratory; 1987.

[45] Allahdadi FA, Carney TC, Hipp JR, Libersky LD, Petschek AG. High strain lagrangian hydrodynamics a three dimensional SPH code for dynamic material response. J Comput Phys 1993;109:67-75.
[46] Johnson GR, Cook WH. A constitutive model and data for metals subjected to large strains, high strain rates and high temperatures. In: In proceedings of 7th international symposium on ballistics, USA 21; 1983. p. 541-7.

[47] Meyer MA. Dynamic behavior of materials. John Wiley \& Sons; USA: 1994.

[48] Li Y, Yang W, Shen W. Influence of linear curvature radius on parameters of explosively formed penetrator (EFP). Initiators Pyrotech 2003;1:45-8 (in Chinese). 